\title{
Photoluminescence Properties of Te Doped AlGaAsSb Alloys
}

\author{
D. O. Toginho Filho, I. F. L. Dias, J. L. Duarte, E. Laureto, \\ Departamento de Física, Universidade Estadual de Londrina, CP 6001, CEP 86051-970, Londrina-Paraná, Brazil \\ and Jean C. Harmand \\ CNRS, Laboratoire de Photonique et de Nanostructures, Route de Nozay, 91460 Marcoussis, France
}

Received on 2 August, 2005

\begin{abstract}
A detailed study of the photoluminescence properties in undoped and Te-doped AlGaAsSb alloys lattice matched to $\mathrm{InP}$ is presented. Photoluminescent temperature and excitation intensity dependences are employed to discuss the origin of the dominant transition and the influence of the presence of $\mathrm{Al}$ and $\mathrm{Te}$ on the fluctuation of the electrostatic potential in the epitaxial layers. The behavior of PL dominant transitions is associated with the quasi-donor-acceptor-pair (QDAP) model at a low temperature interval. The temperature dependence of photoluminescence intensities showed characteristics similar to those observed for amorphous semiconductors and disordered superlattices. The presence of two $\mathrm{V}$ elements, or the presence of $\mathrm{Sb}$ in the ternary and quaternary (III)-III-V-V alloys, causes a reduction in photoluminescence intensity temperature dependence, when compared to (III)-III-III-V alloys.
\end{abstract}

\section{INTRODUCTION}

Recently, there has been great interest in the materials belonging to the group of III-V antimonide family such as $\mathrm{GaAsSb}$ and AlGaAsSb alloys lattice matched to InP due to its applications in heterojunction structures employed in electronic and optoelectronic devices in the range of $1,0 \mu \mathrm{m}$ and 2,0 $\mu \mathrm{m}$ [1-8]. As different semiconductor materials [9-11], the $\mathrm{GaAsSb}$ and AlGaAsSb alloys present fluctuation of the electrostatic potential in the epitaxial layers due to compositional inhomogeneity resulting from miscibility gap [10]. Spontaneous ordering in different planes in GaAsSb alloys prepared by different growth techniques $[12,13]$ has also been reported.

Nominally undoped GaAsSb shows non-excitonic residual acceptor impurity [14], related to native defects such as gallium vacancies and gallium on antimony sites $\left(\mathrm{V}_{G a} \mathrm{Ga}_{S b}\right)$ [15-17], with concentrations of $10^{16} \mathrm{~cm}^{-3}$. PL measurements on undoped $\mathrm{GaAsSb} / \mathrm{InP}$ as a function of the temperature and excitation intensity at low temperatures were used by $\mathrm{Yu}$ et al [10] to identify a high intensity peak in the GaAsSb layer as a donor-acceptor pair (DAP) [18] transition associated with potential fluctuations in agreement with the quasi-donoracceptor-pair (QDAP) model [10,19]. In doped and compensated materials, the random distribution of donor and acceptor impurities [20,21] also causes a fluctuation of the electrostatic potential in the epitaxial layers. Consequently, the random impurity potential disturbs the conduction and valence band edges and the conduction and valence energies are distorted by the random potential. Thus the behaviour of PL transitions can be explained by the QDAP model [10]. In undoped quaternary AlGaAsSb alloys lattice matched to InP, the PL spectra can also be explained by the QDAP model [22]. The presence of aluminum in the quaternary alloy increases the fluctuation of the electrostatic potential in the epitaxial layers as compared to the fluctuation current in the ternary $\mathrm{GaAsSb}$ alloys [22].

In vertical-cavity surface-emitting layers devices (VCSELs), a mirror reflectivity exceeding $99 \%$ and a low electric perpendicular resistance are required for n-type and p- type Bragg mirrors. The high reflectivity is accomplished by employing high refractive contrast material systems such as $\mathrm{AlGaAsSb} / \mathrm{AlAsSb}$ [8] and GaAsSb/AlAsSb [23]. However, these systems present a high band discontinuity, which is unfavorable to the current flow through the heterointerfaces [5]. Then the low electrical resistance requires a relatively high doping level. Therefore, the study of the optical properties of $\mathrm{GaAsSb}$ and $\mathrm{AlGaAsSb}$ doped alloys is very interesting for the technology of fabrication of structures as VCSELs.

$\mathrm{Te}$ is the most common n-type dopant employed in ternary and quaternary arsenide-antimonide alloys [5,8,24,25]. It is possible to obtain high doping levels in GaAsSb, AlGaAsSb and AlAsSb alloys by using the $\mathrm{Sb}_{2} \mathrm{Te}_{3}$ source [3]. However, despite the large interest on the doped AlGaAsSb alloys, a more systematic study of the influence of electrostatic potentials and the effect of the presence of $\mathrm{Al}$ and Te on the optical properties of Te doped $\mathrm{AlGaAsSb}$ alloys has not been found in the literature yet [26,27].

In this work, the optical properties of Te doped AlGaAsSb layers lattice matched to InP with increasing doping concentrations are analyzed. The photoluminescence (PL) as a function of temperature and excitation power is used to investigate the origin of the dominant PL peak in the PL spectra and the influence of aluminum and tellurium on the potential fluctuation in the quaternary layers. Two ternary GaAsSb alloys: one nominally undoped and the other Te doped with a doping level of $\approx 3 \times 10^{18} \mathrm{~cm}^{-3}$ - typical value employed in GaAsSb/AlAsSb [23] and AlGaAsSb/AlAsSb [8] Bragg mirrors - are analyzed to allow a comparison between ternary and quaternary alloys.

\section{EXPERIMENTAL DETAILS}

Undoped and Te doped GaAsSb and AlGaAsSb samples, nominally lattice matched on a (100) $\mathrm{InP}(\mathrm{Fe})$ semi insulating substrate, were grown by MBE. The carrier concentration in Te doped samples $\left(3 \times 10^{17} \mathrm{~cm}^{-3}-9,8 \times 10^{18} \mathrm{~cm}^{-3}\right)$ was determined by Hall measurements at room temperatures using Van 
der Paw methods. Details of the sample parameters such as alloy composition and doping levels can be seen in Table I. PL Table measurements were performed in the temperature range of $10 \mathrm{~K}$ to $300 \mathrm{~K}$, using the $514.5 \mathrm{~nm}$ line of a continuous wave $\mathrm{Ar}^{+}$laser, with different excitation intensities. Temperature variation was obtained by a closed-cycle helium cryostat. The spectral analysis of the luminescence measurements was carried out by a $0.5 \mathrm{~m}$ Jarrel-Ash spectrometer, coupled to a cooled InGaAs photodetector, using the standard lock-in technique.

\section{RESULTS AND DISCUSSION}

Figure 1 shows the PL spectra of samples with an excitation of $532 \mathrm{~W} / \mathrm{cm}^{2}$ at $10 \mathrm{~K}$. The PL peaks of undoped and Te doped ternary alloys are in the lower energy region with dominant transitions at $797 \mathrm{meV}$ and $827 \mathrm{meV}$, respectively. The PL peaks of undoped and Te doped quaternary alloys are in the higher energy region with dominant transitions between $900 \mathrm{meV}$ and $990 \mathrm{meV}$. The energy shift between ternary and quaternary alloys results from the presence of aluminum in quaternary which increases the forbidden gap [28]. The shift of the PL peaks with increasing doping levels to higher energies results from the penetration of the Fermi level into the conduction band, which is typical for n-type doped semiconductor materials [29-31].

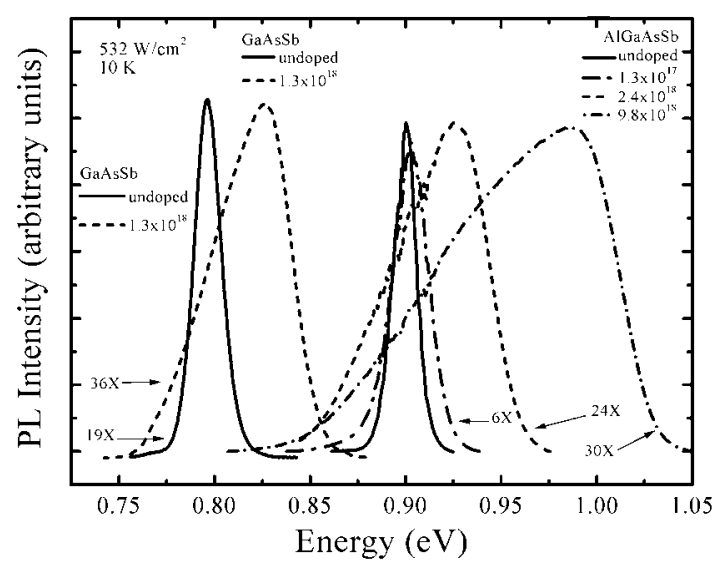

FIG. 1: Photoluminescence spectra of GaAsSb and AlGaAsSb samples, obtained at $10 \mathrm{~K}$ and laser intensity of $532 \mathrm{~W} / \mathrm{cm}^{2}$.

Figure 2 shows the energy of PL peak (Fig. 2a) and the full width at half maximum - FWHM (Fig. 2b) for the doped samples at different doping levels at $10 \mathrm{~K}$. The broadening of the emission spectrum in doped samples with increasing doping concentrations is due, at low side energy, to the evolution of impurity levels into the impurity band of impurity states and the transitions involving band tails states [32] resulting from potential fluctuations of band edges caused by the random distribution of charged impurities [26,33] and variations in the alloy chemical compositions [10]. The higher broadening of the FWHM found in quaternary alloys, when compared to ternary alloys, results from the higher magnitude of the electrostatic potential fluctuations in samples with $\mathrm{Al}[22,33,34]$.
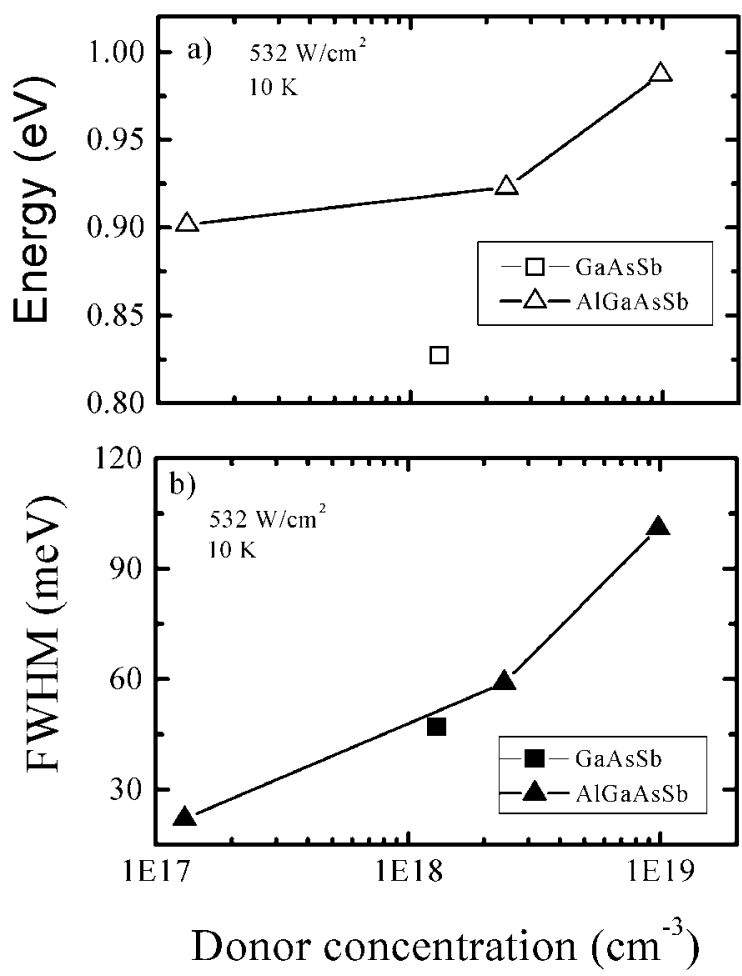

FIG. 2: Donor concentration of PL peak energy (a) and FWHM (b) at $10 \mathrm{~K}$, for $\mathrm{GaAsSb}$ and $\mathrm{AlGaAsSb}$ samples.

The PL spectra of the Te doped GaAsSb for $1.3 \times 10^{18} \mathrm{~cm}^{-3}$ doping concentration recorded at increasing temperatures from $10 \mathrm{~K}$ to $210 \mathrm{~K}$ and of the Te doped $\mathrm{AlGaAsSb}$ for $2.4 \times 10^{18} \mathrm{~cm}^{-3}$ doping concentration obtained between $10 \mathrm{~K}$ to $300 \mathrm{~K}$ temperature range are shown in Fig. 3. The PL spectra show a weak broadening at temperature about $100 \mathrm{~K}$, suggesting the existence of two recombination channels, one predominant at low temperatures $(\mathrm{T}<100 \mathrm{~K})$ and the other dominant at high temperatures.

Energy temperature dependences of dominant PL peak transitions for all samples as a function of the temperature are shown in Fig. 4. The undoped GaAsSb and AlGaAsSb samples present anomalous PL peaks energy dependences on temperature - a characteristic inverted $\mathrm{S}$ - shape - suggesting strong carrier localization, despite the high excitation power employed, as already reported in the literature for this material [22] and for ternary epilayers of undoped AlInAs [36,37]. The PL dominant peak energy of ternary alloy with doping concentration of $1.3 \times 10^{18} \mathrm{~cm}^{-3}$ shows, initially, a weak red shift followed by an interval which remains constant and decreases again with increasing temperatures. The PL peak energy of Te doped AlGaAsSb with doping concentration of $1.3 \times 10^{17}$ $\mathrm{cm}^{-3}$ is similar to that found for undoped AlGaAsSb, showing an inverted $S$ shape, with a weak blue shift $(\approx 1 \mathrm{meV})$ at 
Table I - Alloy composition and Te doping level in the samples used in this work.

\begin{tabular}{|c|c|c|c|c|}
\hline \multirow{2}{*}{ Sample } & \multirow{2}{*}{ Material } & \multicolumn{2}{|c|}{ Alloy Composition } & \multirow{2}{*}{ Te Doping Level $\left(\mathrm{cm}^{-3}\right)$} \\
\hline & & $\mathrm{x}$ & $\mathrm{y}$ & \\
\hline \#T01 & \multirow{2}{*}{$\mathrm{GaAs}_{y} \mathrm{Sb}_{1-y}$} & \multirow{2}{*}{0.00} & \multirow{2}{*}{0.51} & undoped \\
\hline \#66N23 & & & & $1.3 \times 10^{18}$ \\
\hline \#76N46 & \multirow{4}{*}{$\mathrm{Al}_{x} \mathrm{Ga}_{1-x} \mathrm{As}_{y} \mathrm{Sb}_{1-y}$} & \multirow{4}{*}{0.08} & \multirow{4}{*}{0.51} & undoped \\
\hline$\# 76 \mathrm{~N} 43$ & & & & $1.3 \times 10^{17}$ \\
\hline$\# 76$ N39 & & & & $2.4 \times 10^{18}$ \\
\hline$\# 76 \mathrm{~N} 42$ & & & & $9.8 \times 10^{18}$ \\
\hline
\end{tabular}

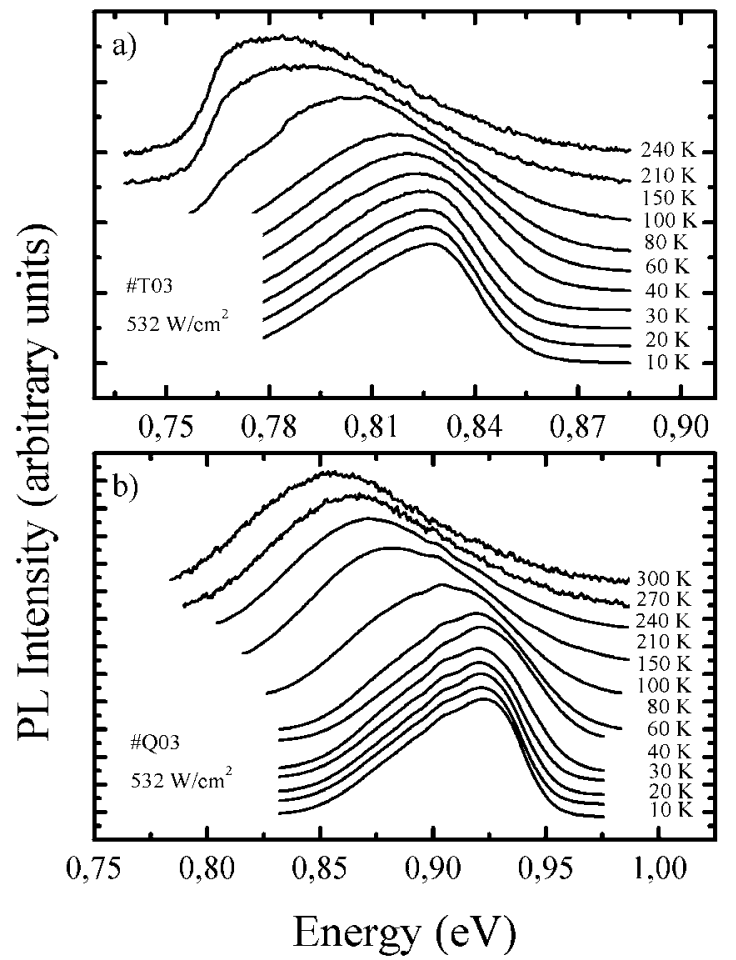

FIG. 3: PL spectra obtained at $532 \mathrm{~W} / \mathrm{cm}^{2}$ laser intensity with temperature variation between $10 \mathrm{~K}$ and $240 \mathrm{~K}$ for GaAsSb samples (a) and between $10 \mathrm{~K}$ and $300 \mathrm{~K}$ for AlGaAsSb samples (b).

low temperatures. The behavior of the PL peak energy in $\mathrm{AlGaAsSb}$ with Te concentration of $2.4 \times 10^{18} \mathrm{~cm}^{-3}$ is similar to that observed in the doped ternary alloy with impurity concentration of the same order. In the most doped Al$\mathrm{GaAsSb}$, the behavior of the PL peak is more complex, showing a lower variation with the temperature growth. It shows a weak red shift at extremely low temperatures $(\mathrm{T}<15 \mathrm{~K})$, remaining nearly constant and, finally, dropping with increasing temperatures. In general, as the doping concentration increases, the anomalous temperature dependence of the dominant PL peak energy decreases, as seen in Si doped AlInAs [36]. In this study, the inverted $\mathrm{S}$ shaped dependence practically disappears for the doped GaAsSb and doped AlGaAsSb alloys at $2.4 \times 10^{18} \mathrm{~cm}^{-3}$. The weakening of the inverted $\mathrm{S}-$

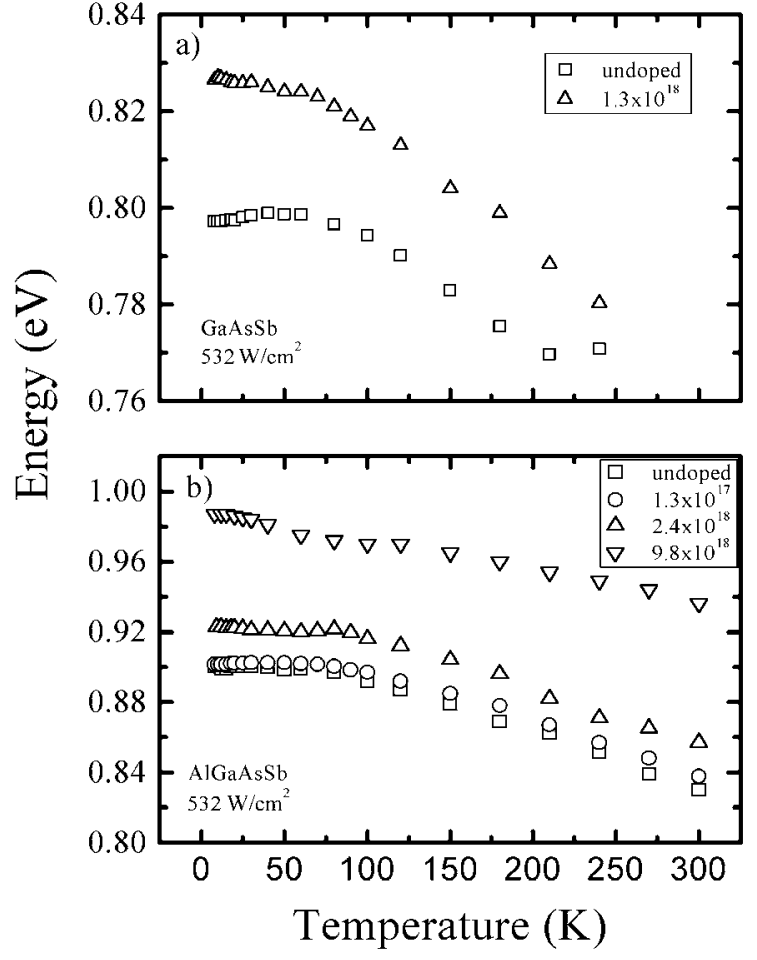

FIG. 4: Temperature dependence of PL peak energy at several laser intensities for GaAsSb (a) and AlGaAsSb samples (b).

shaped dependence on temperature of the dominant PL peak energy with increasing impurity concentrations cannot be directly associated to a reduction in the disorder of the epitaxial layers. In a process similar to that found for AlInAs:Si [36], the donor binding energy is reduced at high doping levels, causing a higher dopant ionization as the temperature rises. Later in this article, we will discuss the role of the doping level growth and the presence of $\mathrm{Al}$ in the order/disorder phenomenon.

Figure 5 shows the temperature dependence of FWHM of the PL peaks obtained at an excitation intensity of $532 \mathrm{~W} / \mathrm{cm}^{2}$. For a better experimental data comparison, the FWHM of the doped ternary alloy and of the two most doped quaternary alloys are shown by subtracting the real values by $10 \mathrm{meV}, 25$ $\mathrm{meV}$ and $50 \mathrm{meV}$, respectively. In general, the FWHM of 
the emission spectrum in an alloy is determined by the impurity ionization and compositional fluctuations of the epitaxial layer [38]. The FWHM of the PL peak energy of undoped GaAsSb shows an increasing broadening $(18 \mathrm{meV}$ to $34 \mathrm{meV}$ ) in the $10 \mathrm{~K}$ to $180 \mathrm{~K}$ temperature interval, reaching a maximum at $180 \mathrm{~K}$, and a decreasing in higher temperatures. This behavior is similar to that observed for non- intentionally doped $\mathrm{In}_{0.52} \mathrm{Al}_{0.48} \mathrm{As}$, where the FWHM initially increases due to thermal broadening and, subsequently, decreases due to the gradual ionization of impurities with increasing temperatures [37]. The FWHM of doped GaAsSb shows a general behavior very similar to that observed in the undoped GaAsSb. The FWHM of the doped AlGaAsSb rises in the $10 \mathrm{~K}$ to $300 \mathrm{~K}$ temperature interval. The presence of $\mathrm{Al}$ increases the binding energy in the donor impurity, and the transitions associated with this impurity which is present in the PL spectrum of Te doped AlGaAsSb at room temperature, preventing the FWHM from falling in the temperature interval analyzed.

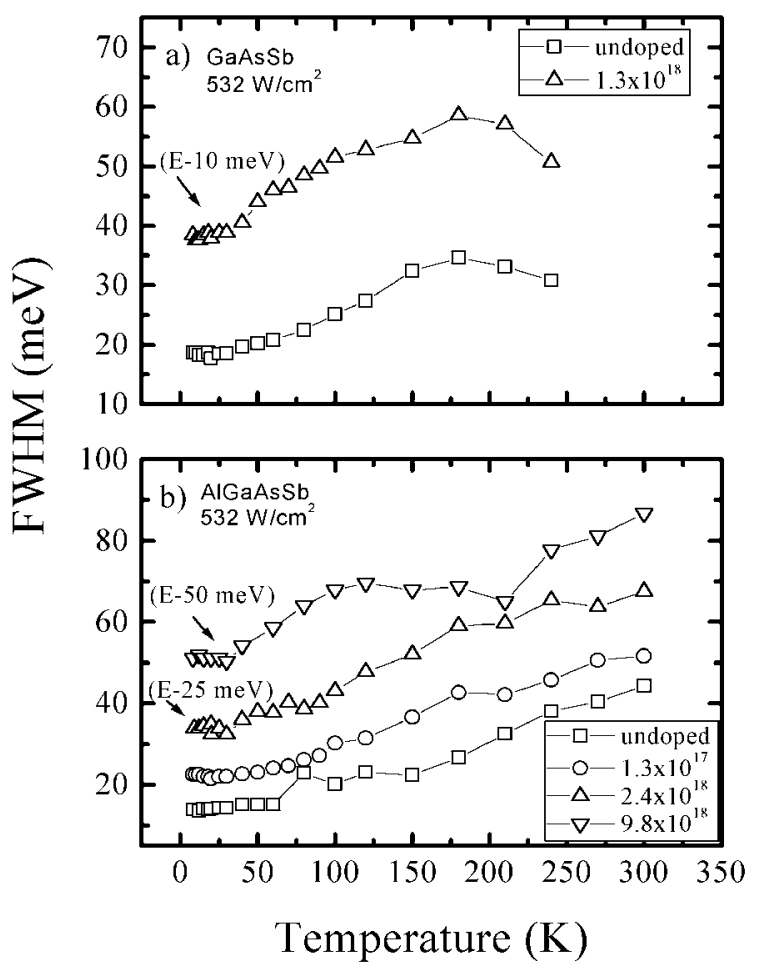

FIG. 5: Temperature dependence of FWHM peak energy at 532 $\mathrm{W} / \mathrm{cm}^{2}$ laser intensities for GaAsSb (a) and AlGaAsSb samples (b).

The integrated PL intensity of the dominant transition (I) and the excitation intensity $(\mathrm{J})$ are related by the expression $[35] I \propto J^{k}$, and for free electron - impurity (electron-acceptor, eA, or donor-hole, Dh) or donor-acceptor pair (DAP) the exponent is less than unity [35]. This analysis was carried out for CdTe, and can be applied to other semiconductor materials with direct band gaps $[35,39,40]$. Values of $k$ obtained from the analysis of the integrated PL intensity as function of intensity excitation can be seen in Table II. These results indicate that the dominant transitions in our PL spectra are related to a band-impurity or donor-acceptor recombination in all samples. In the quaternary doped alloys the acceptor level is probably the same residual acceptor impurity [14] related to native defects such as gallium vacancies and gallium on antimony sites $\left(\mathrm{V}_{G a} \mathrm{Ga}_{S b}\right)$ [16] also found in the GaSb [15] and $\mathrm{GaAsSb}$ [17].

Table II - Parameters obtained of the experimental data at $10 \mathrm{~K}$ for the PL intensity dependence with the laser intensity, for GaAsSb and $\mathrm{AlGaAsSb}$ samples. The fit is carred out using the $I=A$. $J^{k}$ expression, where $I$ is the PL peak intensity and $J$ is the laser intensity.

\begin{tabular}{|l|l|l|l|}
\hline \multirow{2}{*}{ Sample } & \multirow{2}{*}{ Material } & $A$ & $k$ \\
\hline \#T01 & \multirow{2}{*}{$\mathrm{GaAs}_{y} \mathrm{Sb}_{1-y}$} & 0.13 & 0.70 \\
\cline { 4 - 4 } \#66N23 & & 0.06 & 0.75 \\
\hline \#76N46 & & 0.26 & 0.90 \\
\hline \#76N43 & \multirow{3}{*}{$\mathrm{Al}_{x} \mathrm{Ga}_{1-x} \mathrm{As}_{y} \mathrm{Sb}_{1-y}$} & 0.04 & 0.83 \\
\cline { 4 - 4 } & & 0.11 & 0.67 \\
\cline { 1 - 1 } \#76N39 & 0.06 & 0.85 \\
\hline \#76N42 & &
\end{tabular}

Dominant PL peak (E) energy variations compared to the energies obtained at lower excitation intensities $\left(\mathrm{E}_{0}\right)$ as a function of power excitation at $10 \mathrm{~K}$ are shown in Fig. 6. Undoped GaAsSb PL dominant peak energy shows a blue shift (3.6 meV/decade) as a function of the laser intensity. The behavior of the PL peak energies for all samples (except the most doped $\mathrm{AlGaAsSb}$ ) is the same, indicating that the main emission is related to the transition type DAP [35] or QDAP [10]. PL peak energy shifts as a function of excitation intensities of about $3 \mathrm{meV} / \mathrm{decade}$ are reported in the literature for strained $\mathrm{GaAs}_{0,69} \mathrm{Sb}_{0,31}$ on InP [10], for strongly doped compensated systems $[18,41,42]$ due to the fluctuations of electrostatic potential, and also for weak ordered systems [43].

Figure 7 shows the variation of FWHM for PL peaks with excitation power at $10 \mathrm{~K}$, for ternary alloys (Fig. 7a), and for quaternary alloys (Fig. 7b). The FWHM of undoped GaAsSb and doped GaAsSb show a broadening of $9.5 \mathrm{meV}$ and 9.8 $\mathrm{meV}$, respectively, with increasing excitation power in the interval of laser intensities employed in this work $\left(\approx 1 \mathrm{~W} / \mathrm{cm}^{2}\right.$ to $\approx 10^{3} \mathrm{~W} / \mathrm{cm}^{2}$ ). In general, the gradual increase in FWHM is associated with the increase in the number of ionized impurities and in the magnitude of compositional fluctuations in the alloy. The number of ionized impurities increases with increasing excitation power, changing the line shape of the spectrum. In contrast, the broadening associated with the compositional fluctuation is independent of the excitation density [38]. FWHM total variation in undoped $\mathrm{AlGaAsSb}$ is $4.3 \mathrm{meV}$ in the laser intensity range employed here, indicating that the presence of $\mathrm{Al}$ in the quaternary alloy can reduce the number of ionized impurities as compared to ternary alloys under the same condition due, probably, to the increase in the binding donor of unknown donor. The AlGaAsSb sample with $1.3 \times 10^{17} \mathrm{~cm}^{-3}$ doping level shows a similar broadening of the PL emission (5.1 meV/decade). The PL peaks of the highest doped samples $\left(2.4 \times 10^{18} \mathrm{~cm}^{-3}\right.$ and $\left.9.8 \times 10^{18} \mathrm{~cm}^{-3}\right)$ show 


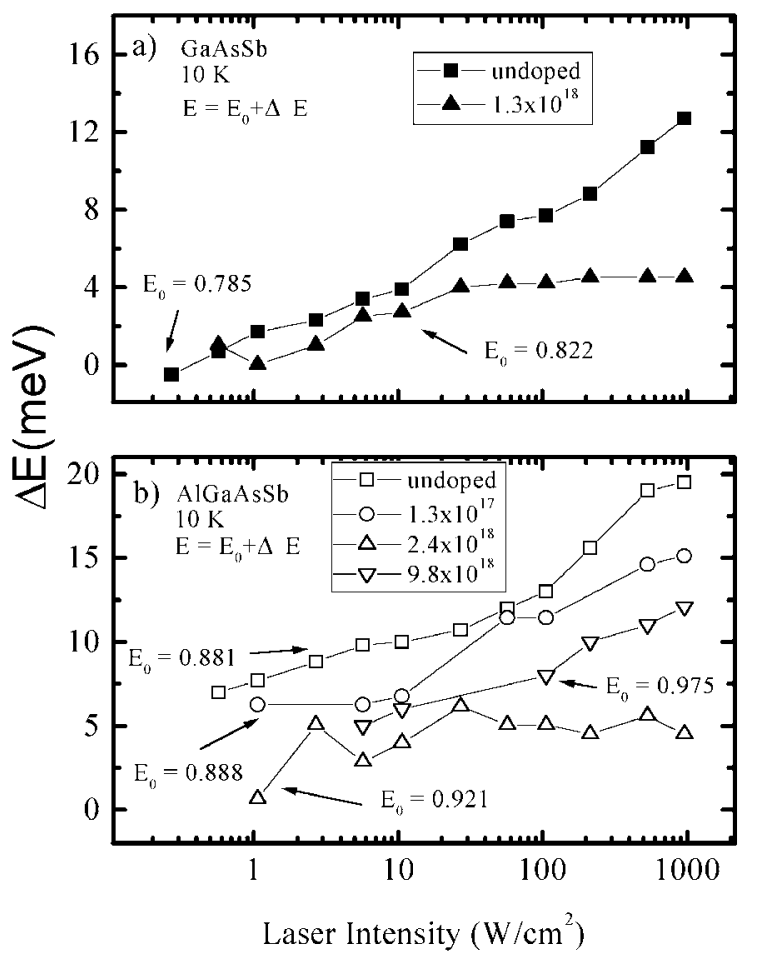

FIG. 6: Laser intensity dependence of peak energy at $10 \mathrm{~K}$ for $\mathrm{GaAsSb}(\mathrm{a})$ and $\mathrm{AlGaAsSb}$ samples (b).

a higher broadening with increasing power excitation $(\approx 5$ meV/decade). The growth of FWHM as a function of the doping level indicates the presence of a higher number of ionized impurities, and can be associated to the reduction of the $\mathrm{Te}$ donor binding energy involved in the transitions.

Temperature dependence of the integrated PL intensity in the $10 \mathrm{~K}$ to $210 \mathrm{~K}$ range for the ternary undoped and Te doped ternary alloys are shown in Fig. 8a), and for the undoped and Te doped quaternary alloys in Fig. 8b), at the excitation intensity of $532 \mathrm{~W} / \mathrm{cm}^{2}$. Due to the presence of localized states, the standard Arrhenius plot cannot be used to fit the integrated PL intensity versus temperature data. The temperature dependence of the integrated PL intensity can be fitted well, using an expression deduced from amorphous semiconductors [37,44]:

$$
I_{P L}=I_{0} /\left[1+A \cdot \exp \left(T / T_{0}\right)\right]
$$

Where $\mathrm{I}_{P L}$ is the normalised intensity of the PL peak, $\mathrm{T}$ is the measurement temperature, $\mathrm{T}_{0}$ is the characteristic temperature associated with the energy depth of localized states, A is the tunnelling factor and $I_{0}$ is the luminescence intensity at the low temperature limit.

The PL intensity as a function of temperature shows a discontinuity $\left(T_{D}\right)$ for all samples similar to that reported in the literature for $\mathrm{Al}_{0.5} \mathrm{Ga}_{0.5} \mathrm{As}$ bulk and disordered superlattices

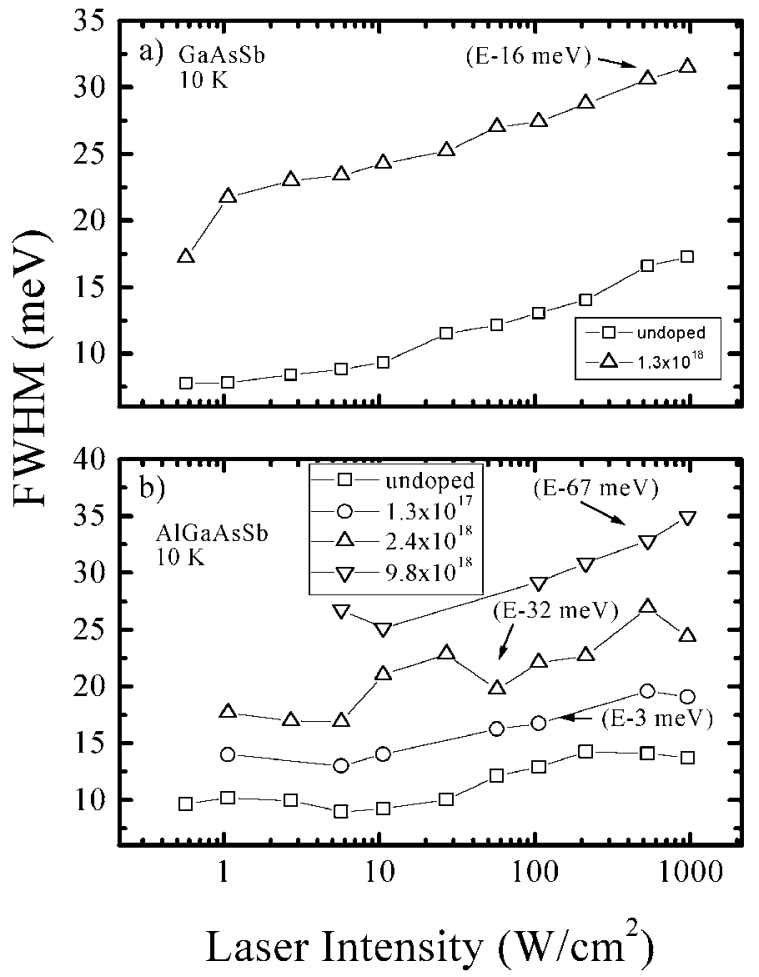

FIG. 7: Laser intensity of FWHM peak energy at $10 \mathrm{~K}$ for GaAsSb (a) and AlGaAsSb samples (b).

[37], for undoped [36,38] and Si doped AlInAs [36] at doping levels between $1 \times 10^{17} \mathrm{~cm}^{-3}$ and $4 \times 10^{18} \mathrm{~cm}^{-3}$, and for undoped GaAsSb and AlGaAsSb [22]. This discontinuity is about $\mathrm{T}_{D} \approx 120 \mathrm{~K}$ for the ternary alloys and $\mathrm{T}_{D} \approx 100$ $\mathrm{K}$ for the quaternary alloys. $\mathrm{T}_{0}$ values above and below the discontinuity obtained from the literature and the fitting of the experimental data reported in Figure 8 using the expression (1) are given in Table III.

The analysis of Table III shows that for higher disordered materials or materials with strong localization of carriers, due to the presence of electrostatic potential fluctuations associated with higher alloy complexities, higher number of defects or higher number of impurities, the PL intensities are less sensitive to temperature variations compared to that obtained for random or undoped alloys. The undoped and doped epilayers composed by III-III-V elements, as AlGaAs and AlInAs, show $\mathrm{T}_{0}$ values systematically lower than those obtained for alloys composed by III-V-V elements for temperatures below and above $\mathrm{T}_{D}$. Antimonide alloys characterized by two $\mathrm{V}$ elements present higher potential fluctuations and defect concentrations due probably to the effect of the presence of $\mathrm{Sb}$ (an element with a large atomic diameter) and/or the presence of two elements $\mathrm{V}$ (As and $\mathrm{Sb}$ ), which makes it more difficult to obtain a random character for the epitaxial layers in the sample preparation. This could give a higher $\mathrm{T}_{0}$ and, consequently, a lower sensibility of the PL peak intensities to the 
Table III - Parameters obtained of literature and fitting using the $I_{P L}=I_{0} /\left[1+A \cdot \exp \left(T / T_{0}\right)\right]$ expression in the experimental data for GaAsSb (Fig. 8a) and AlGaAsSb (Fig. 8b) samples, with laser intensity at 532 Watts $/ \mathrm{cm}^{2}$.

\begin{tabular}{|c|c|c|c|c|}
\hline Alloy & Material & $\mathrm{T}_{0}<\mathrm{T}_{D}$ & $\mathrm{~T}_{0}>\mathrm{T}_{D}$ & Reference \\
\hline \multirow{3}{*}{ III-III-V undoped } & $\mathrm{Al}_{0.45} \mathrm{Ga}_{0.55} \mathrm{As}$ & 4.8 & - & 37 \\
\hline & $\mathrm{Al}_{0,48} \mathrm{In}_{0,52} \mathrm{As}$ & 17 & 28 & 38 \\
\hline & $\mathrm{Al}_{0,48} \operatorname{In}_{0,52} \mathrm{As}$ & 8 & 21 & 36 \\
\hline \multirow{3}{*}{ III-V-V undoped } & $\mathrm{GaAs}_{0,51} \mathrm{Sb}_{0,49}$ & 36.6 & 49.6 & 22 \\
\hline & $\mathrm{Al}_{0,07} \mathrm{Ga}_{0,93} \mathrm{As}_{0,51} \mathrm{Sb}_{0,49}$ & $30 \pm 1$ & $57 \pm 2$ & this work \\
\hline & $\mathrm{Al}_{0,12} \mathrm{Ga}_{0,88} \mathrm{As}_{0,51} \mathrm{Sb}_{0,49}$ & 20.7 & 60.3 & 22 \\
\hline \multirow{3}{*}{ III-III-V doped } & AlInAs:Si $\left(1 \times 10^{17}\right)$ & 10 & 37 & 36 \\
\hline & AlInAs:Si $\left(6 \times 10^{\Gamma \prime}\right)$ & 19 & 45 & 36 \\
\hline & AlInAs:Si $\left(4 \times 10^{18}\right)$ & 40 & 50 & 36 \\
\hline \multirow{4}{*}{ III-V-V doped } & GaAsSb:Te $\left(1,3 \times 10^{18}\right)$ & $38 \pm 1$ & $79 \pm 3$ & this work \\
\hline & AlGaAsSb:Te( $\left(1,3 \times 10^{17}\right)$ & $48 \pm 2$ & $57 \pm 2$ & this work \\
\hline & AlGaAsSb:Te $\left(2,4 \times 10^{17}\right)$ & $35 \pm 2$ & $88 \pm 3$ & this work \\
\hline & AlGaAsSb:Te $\left(9,8 \times 10^{17}\right)$ & $39 \pm 2$ & $124 \pm 11$ & this work \\
\hline
\end{tabular}

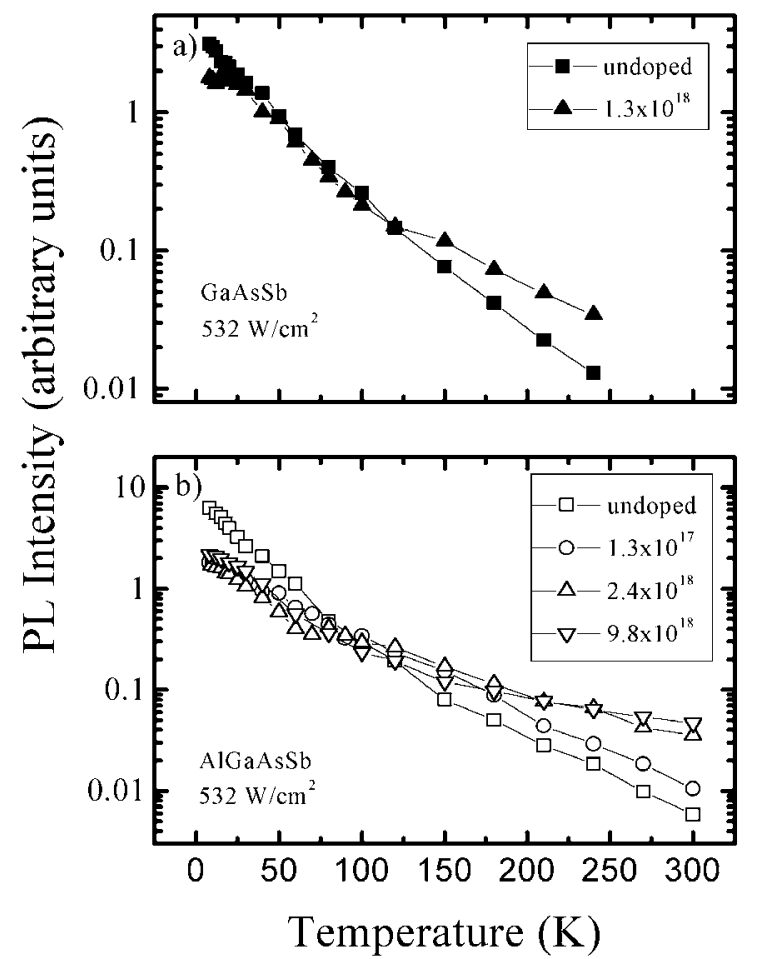

FIG. 8: Temperature dependence of PL intensity for the GaAsSb (a) and $\mathrm{AlGaAsSb}$ samples (b) obtained at $532 \mathrm{~W} / \mathrm{cm}^{2}$, fitted with equation (1).

temperature variations

Undoped AlGaAsSb samples show a reduction in $\mathrm{T}_{0}$ for temperatures below $\mathrm{T}_{D}$ when $\mathrm{Al}$ concentration increases. This behavior can be associated with a growth in binding energy of unknown donor impurity caused by an increase in $\mathrm{Al}$ concen- tration. An increase in donor level energy can have a similar effect to that caused by a decrease in ionization energy with the growth of donor impurities reported by Yoon et al [36] for Si doped AlInAs. In that case, the growth in dopant concentrations implicates in a higher donor ionization due to the reduction in donor energy and not in disorder. In this work, we believe that a lower donor binding energy of the unknown donor in the GaAsSb gives a similar effect when compared to a higher donor binding energy in AlGaAsSb.

To analyse Te doped GaAsSb and AlGaAsSb epilayers, we need to consider initially that the donor impurity Te (element VI) occupies, preferentially, the As or Sb (elements V) sites in the crystal lattice. For alloys such as AlGaAs and AlInAs, Si (element IV) is the element most employed as donor impurity, and it occupies, preferentially, the Al, Ga or In (elements III) sites. Table III shows that, for doped AlGaAsSb at temperatures below $\mathrm{T}_{D}$, the $\mathrm{T}_{0}$ initially decreases and subsequently increases with increasing doping levels. This reduction in $\mathrm{T}_{0}$ value can be related to a possible contribution of the Te impurities, at moderate concentrations, to the reduction in native defects in alloys of the Sb family, as reported by J.Diaz et al [45] in InGaAsSb alloys prepared by LPE (liquid phase epitaxy). A more systematic work is needed to elucidate this question.

\section{CONCLUSION}

In this study, we have reported photoluminescence of undoped and Te doped GaAsSb and AlGaAsSb alloys nominally lattice matched to InP, grown by MBE as a function of temperature and excitation intensities. At low temperatures the dominant PL peak transition is related to donor and acceptor recombinations in alloys with potential fluctuation consistent with the quasi-donor-acceptor-pair (QDAP) model. The donor element is associated to a donor impurity of unknown origin in the case of undoped samples and to Te in the case of doped samples. The acceptor is related to native defects such gallium vacancies and gallium on antimony sites. Type III-V-V ternary 
alloys show higher potential fluctuation and defect concentrations as compared to that observed for ternary alloys type IIIIII-V. The presence of two V elements or the presence of Sb in alloys (III)-III-V-V reduces the sensibility of the PL intensity to temperature variations. The PL intensity of undoped and Te doped quaternary alloy shows a temperature dependence similar to that found for amorphous semiconductors and disordered superlattices. The presence of Te seems to cause an increase in the sensibility of the PL intensity to temperature variations at moderate concentrations.

\section{Acknowledgements}

The authors wish to thank the financial support granted by the Brazilian agencies CAPES, CNPq, Fundação Araucária and Fundação Banco do Brasil
[1] B. Lambert, Y. Toudic, Y. Rouillard, M. Baudet, B. Guenais, B. Deveaud, I. Valiente, and J. C. Simon, Appl. Phys. Lett. 64, 690 (1994).

[2] O.Blum, I.J.Fritz, L.R.Dawson, and T.J.Drummond, Electron. Lett. 31, 1247 (1995).

[3] I. F. L. Dias, B. Nabet, A. Kohl, and J. C. Harmand, Electron. Lett. 33, 716 (1997).

[4] N.Kuze, H.Goto, M.Matsui, I.Shibasaki, H.Sakaki, J. Cryst. Growth 175/176, 868 (1997).

[5] I. F. L. Dias, B. Nabet, A. Kohl, J. L. Benchimol, and J. C. Harmand, IEEE Photon. Technol. Lett. 10, 763 (1998).

[6] J.C. Harmand, G. Ungaro, I. Sagnes, J.P. Debray, B. Sermage, T. Rivera, C. Meriadec, J.L. Oudar, R. Raj, F. Olivier-martin, C. Kazmierski, R. Madani, J. Cryst. Growth 201/202, 837 (1999).

[7] L. Chusseau, G. Almuneau, F. Genty, Recent Research Developments in Quantum Electronics, Vol. 1, 85 (1999) .

[8] D.O. Toginho Filho, I.F.L.Dias, J.L.Duarte, S.A.Lourenço, L.C.Poças, E.Laureto, J.C.Harmand, Superlattices Microstruct. 31, 277 (2002)

[9] T H Chiu, W.T.Tsang, S.N.G.Chu, J.Shah, and J.A.Ditzenberger, Appl. Phys. Lett. 46, 408 (1985).

[10] P.W.Yu, C. E. Stutz, M. 0. Manasreh, R.Kaspi, M.A.Capano, J. Appl. Phys. 76, 504 (1994).

[11] B. Shin, A. Lin, K. Lappo, R.S. Goldman, M.C. Hanna, S. Francoeur, A.G. Norman, A. Mascarenhas, Appl. Phys. Lett. 80, 3292 (2002).

[12] J. J. Murgatroyd, A. G. Norman, and G. R. Booker, J. Appl. Phys. 67, 2310 (1990).

[13] H R Jen, M. J. Cherng, and G. B. Stringfellow, Appl. Phys. Lett. 48, 1603 (1986).

[14] K.G. Merkel, V. M. Bright, M. A. Marciniak, C. L. A. Cerny and M. O. Manasreh, Appl. Phys. Lett. 65, 2442 (1994).

[15] P. S. Dutta, H. L. Bhat, and Vikram Kumar, J. Appl. Phys. 81 5821 (1997).

[16] M. Ichimura, K. Higuchi, Y. Hattori, T. Wada, and N. Kitamura, J. Appl. Phys. 68, 6153 (1990).

[17] Y.Nakata, T.Jujii, A.Sandhu, Y.Sugiyama, and E.Miyauchi, J. Cryst. Growth 91, 655 (1987).

[18] P.W.Yu, C.K. Peng and H.Morkoç, J. Appl. Phys. 65, 2427 (1989).

[19] D. R. Chamberlin, S. S. Yi, D. Isaacson, G. Girolami, and N. Moll, Appl. Phys. Lett. 83, 2375 (2003).

[20] V.P.Dobrego, I.S.Shlimak, Phys. Stat. Sol. 33, 805 (1969).

[21] V Swaminathan, V.M.Donelly, and J.Long, J. Appl. Phys. 58, 4565 (1985).

[22] D. O. Toginho Filho, I. F. L. Dias, E. Laureto, J. L. Duarte, S. A. Lourenço, L. C. Poças, S. S. Prabhu, and J. Klem, J. Appl. Phys. 97, 123702 (2005).
[23] F. Genty, G. Almuneau, L. Chusseau, Wilk, S. Gaillard G. Boissier, P. Grech, J. Jacquet, J. Cryst. Growth 201/202, 1024 (1999).

[24] P.S. Dutta, B. Mendez, J. Piqueras, E. Dieguez, and H. L. Bhat, J. Appl. Phys. 80, 1112 (1996).

[25] F. Genty, G. Almuneau, L. Chusseau, G. Boissier, J.P. Malzac, P. Salet, and J. Jacquet, Electron. Lett. 33, 140 (1997).

[26] M.S. Noh, R.D. Dupuis, D.P. Bour, G. Walter, N. Holonyak, Appl. Phys. Lett. 83, 2530 (2003).

[27] C.A. Wang, R.K. Huang, D.A. Shiau, M.K. Connors, P.G. Murphy, P.W. O'Brien, A.C. Anderson, D.M. DePoy, G. Nichols, M.N. Palmisiano, Appl. Phys. Lett. 83, 1286 (2003).

[28] R. E. Nahory, and M. A. Pollack, Appl. Phys. Lett. 27, 562 (1975).

[29] Jiang De-Sheng, Y. Makita, K. Ploog, H.J. Queisser, J. Appl. Phys. 53, 999 (1982).

[30] Jukka A Lahtinen, Phys. Rev. B 33, 2550 (1986).

[31] M. Cardona, K. L. Shaklee, F. H. Pollak, Phys. Rev. 154, 696 (1967).

[32] Jacques I. Pankove, Optical Processes in Semiconductors, Dover Publications. Inc., (1971), p10.

[33] E. F. Schubert, I. D. Goepfert, W. Grieshaber, and J. M. Redwing, Appl. Phys. Lett. 71, 921 (1997).

[34] E. Iliopoulos, D. Doppalapudi, H. M. Ng, and T. D. Moustakas, J. Appl. Phys. 73, 375 (1998).

[35] L.Pavesi, M.Guzzi, J. Appl. Phys. 75, 4779 (1994).

[36] S. F. Yoon, Y. B. Miao,K. Radhakrishnan, and H. L. Duan, J. Appl. Phys. 78, 1812 (1995).

[37] T. Yamamoto, M. Kasu, S. Noda, A. Sasaki, J. Appl. Phys. 68, $5318(1990)$

[38] S.M.Olsthoorn, F.A.J.M Driessen, A.P.A.M. Eijkelenboom, L.J. Giling, J. Appl. Phys. 73, 7798 (1993).

[39] T.Schmidt, K.Lischka, and W.Zulehner, Phys. Rev. B 45, 8989 (1992).

[40] A. Aydinli, N. M. Gasanly, and K. Goksen, J. Appl. Phys. 88, 7144 (2000).

[41] P.W.Yu, J. Appl. Phys. 48 , 5043 (1977).

[42] H. P. Gislasoh, E, H. Yang, and M. Linnarson, Phys. Rev. B 47, 9418 (1993).

[43] M. C. Delong, P. C. Taylor, and J. M. Olson, Appl. Phys. Lett. 57, p620, 1990.

[44] R. A. Street, T. M. Searle, and I. G. Augustine, in Amorphous and Liquid Semiconductors, edited by J. Stoke and W. Brenig (Taylor and Francis, London, 1974), p. 953.

[45] J.Diaz-Reyes, J. L. Herrera-Perez, M. L. Gomez-Herrera, J. A. Cardona-Bedoya, and J. G. Mendoza-Alvarez, Appl. Surf. Sci. 238, 400 (2004). 